\title{
Diagnóstico da situação e perspectivas do ensino na Faculdade de Medicina de Botucatu (UNESP, 1978)
}

Augusto Cezar Montelli*; Cecilia Magaldi*; Mario A.C.L. Ribeiro**; Sheila Z. de Pinho**; Marcelo F. de Franco*; Elson F. Mendes*; Domingos Alves Meira*; Laurival A. de Luca*; Mariza M. Meirelles* e J. Fausto B. Domingues***

\section{Introdução}

A Faculdade de Medicina de Botucatu (FMB) formou de 1968 a 1978 ao redor de 1.000 médicos. Implantada em 1963, até 1976 constituiu com outros três cursos Biologia, Agronomia e Medicina Veterinária - a Faculdade de Ciências Médicas e Biológicas de Botucatu (FCMBB), cuja estrutura fundamentava-se no ensino básico comum aos quatro cursos profissionalizantes.

O curso de aplicação em Medicina em seus diferentes aspectos e algumas reformulações já foi objeto de inúmeros trabalhos $^{1,2,3,5,7,11}$, mas as repercussões do progresso material verificado em 16 anos sobre a qualidade do ensino não foram, até o momento, devidamente avaliadas, principalmente face à proposta já formulada em $1966^{6} \mathrm{e}$ reafirmada em $1968^{7}$ de formação do médico geral.

Como decorrência do modelo de assistência médica vigente no período, as Escolas Médicas têm preparado de preferência profissionais para uma Medicina de mercado. Reformulações substanciais no atual sistema de saúde estão sendo propostas e, como conseqüência, dá-se ênfase nos últimos anos à for- mação do médico geral objetivando ampliar a cobertura e extensão dos serviços e baratear os seus custos ${ }^{14,12}$.

Diante destes fatos e da necessidade de avaliar a situação do ensino médico ministrado pela FMB, com a finalidade de redefinir objetivos e propor reformulações curriculares, a Câmara de Graduação, em 1978, propôs-se a um diagnóstico com base nas opiniões de docentes, alunos e médicos residentes desta Instituição.

\section{Levantamento de Dados}

As opiniões e informações foram colhidas em setembro-outubro de 1978, mediante o preenchimento de 3 tipos de questionários: um para os docentes do curso básico, outro para os do curso aplicado em medicina e um terceiro para residentes e internos (alunos do 60 ano). Apenas os questionários dos docentes foram identificados, sendo todos eles devolvidos em torno de 15 dias.

A tabela 1 apresenta as coberturas atingidas nos quatro grupos consultados.
* Membros da Câmara de Graduação da Faculdade de Medicina de Botucatu.

**Docentes do Departamento de Bioestatística do IBBMA - UNESP.

* * *Assistente técnico-acadêmico da Faculdade de Medicina de Botucatu. 
TABELA 1 - COBERTURA OBTIDA NOS GRUPOS CONSULTADOS (Botucatu, 1978).

\begin{tabular}{|l|c|c|c|}
\hline Grupo & $\begin{array}{l}\text { No to- } \\
\text { tal }\end{array}$ & $\begin{array}{l}\text { No dos } \\
\text { que res- } \\
\text { ponde- } \\
\text { ram }\end{array}$ & $\begin{array}{l}\text { Cobertu- } \\
\text { ra (\%) }\end{array}$ \\
\hline $\begin{array}{l}\text { Docentes curso } \\
\text { básico( }{ }^{1} \text { ) }\end{array}$ & 56 & 35 & 62,5 \\
$\begin{array}{l}\text { Docentes curso } \\
\text { aplicado }\end{array}$ & 140 & 115 & 81,5 \\
Internos & 85 & 72 & 84,7 \\
Residentes & 100 & 66 & 66,0 \\
\hline TOTAL & 381 & 288 & 75,6 \\
\hline
\end{tabular}

(1) Apenas os docentes do Instituto Básico de Biologia Médica e Agrícola que ministraram o curso básico aos alunos matriculados na Faculdade de Medicina, 1978.

As respostas foram codificadas e analisadas no Departamento de Bioestatística do IBBMA (UNESP).

Para análise e comparação dos dados foram utilizados os seguintes critérios:

1) Comparação de respostas dos docentes do curso básico e aplicado, quando as questões eram idênticas;

2) Comparação das respostas dos internos e residentes;

3) Consideração das seguintes categorias para análise interna das respostas dos docentes:

a) classificação dos departamentos da área aplicada segundo conteúdos "geral" ou "especializado" dos cursos ministrados; b) classificação dos departamentos da área aplicada segundo a atividade "clínica", "cirúrgica" ou em "anatomia patológica" de seus docentes;

c) classificação dos departamentos da área básica de acordo com os conteúdos dos cursos em: morfologia, fisiologia, patologia (microbiologia, parasitologia e imunologia) e outros (genética e bioestatística).

$\mathrm{Na}$ análise estatística as diferenças entre parâmetros da multinomial foram testadas pelo método de Goodman ${ }^{10}$. As comparações entre parâmetros de várias multinomiais foram estabelecidas pelo método de Goodman ${ }^{9}$. O teste de duas proporções correlacionadas foi feito pela estatística de Mc $\mathrm{Nemar}^{8}$ e o de duas proporções independentes pelo Qui-quadrado de Pearson ${ }^{8}$. A comparação de várias proporções correlacionadas foi feita pela estatística de Cochran-Fleiss ${ }^{8}$. A homogeneidade de várias tabelas de $\mathbf{2 X} \mathbf{2}$ foi testada pela estatística de MantelHaenszel $^{8}$.

O nível de significância adotado em todos os testes foi de $5 \%$.

Expressões referentes a diferenças (maior, menor, diferente) encontradas no texto dizem respeito a diferenças estatisticamente significantes.

\section{Resultados e Comentários}

\subsection{O médico que a Faculdade de Medicina forma e o que deverá formar}

$\mathrm{Na}$ tabela 2 encontram-se as opiniões dos docentes quanto ao tipo de médico que a Faculdade forma. 
VOL. IV NÚMERO 3 SET/DEZ 1980

TABELA 2 - O TIPO DE MÉDICO QUE A FACULDADE FORMA, SEGUNDO DOCENTES (Botucatu, 1978).

\begin{tabular}{|l|c|c|c|c|}
\hline \multirow{2}{*}{ Docentes } & \multicolumn{2}{c|}{ CURSO BÁSICO } & \multicolumn{2}{c|}{ CURSO APLICADO } \\
\cline { 2 - 5 } & No & $\%$ & No & $\%$ \\
\hline Médico Geral & 5 & 14,0 & 11 & 10,0 \\
Clínico Geral & - & - & 28 & 24,0 \\
Especialista & 3 & 9,0 & 9 & 8,0 \\
Não bem caracterizado & 13 & 37,0 & 46 & 40,0 \\
Não sei & 14 & 40,0 & 15 & 13,0 \\
Outras respostas & - & - & 6 & 5,0 \\
\hline TOTAL & 35 & 100,0 & 115 & 100,0 \\
\hline
\end{tabular}

Segundo a maioria dos docentes a Faculdade forma um médico não bem caracterizado. Nota-se ainda que $40 \%$ dos docentes do básico não se considerou em condições de responder; entretanto, não houve diferença entre proporções de respostas "não sei" e "não bem caracterizado". As respostas do conjunto dos docentes mostram dificuldade em se definir o tipo de médico que atualmente se forma na Faculdade de Medicina. A análise das respostas, segundo os grupos departamentais estabelecidos, revelou o mesmo grau de dificuldade.
Quanto ao médico que a Faculdade deve formar, a opinião que prevaleceu foi a do médico geral em todos os grupos considerados, como mostra a tabela 3. Apenas para os docentes do básico não houve diferença entre as respostas para clínico geral e médico geral. A proporção de respostas "médico geral" desse grupo foi menor que as demais, não havendo diferenças nas proporções para os demais grupos. A proporção de respostas para médico geral dadas por docentes de anatomia patológica foi maior que a dos docentes clínicos e cirurgiões.

TABELA 3 - TIPO DE MÉDICO QUE A FACULDADE DE MEDICINA DEVERÃ FORMAR (Botucatu, 1978).

\begin{tabular}{|l|r|r|r|r|r|r|r|r|}
\hline \multirow{2}{*}{ Respostas } & \multicolumn{2}{|c|}{$\begin{array}{c}\text { Docentes do } \\
\text { Básico }\end{array}$} & \multicolumn{2}{c|}{$\begin{array}{c}\text { Docentes do } \\
\text { Aplicado }\end{array}$} & \multicolumn{2}{c|}{ Internos } & \multicolumn{2}{c|}{ Residentes } \\
\cline { 2 - 9 } & No & $\%$ & \multicolumn{1}{|c|}{ No } & $\%$ & No & $\%$ & No & $\%$ \\
\hline Médico Geral & 15 & 42,9 & 91 & 79,1 & 59 & 82,0 & 47 & 71,0 \\
Clínico Geral & 7 & 20,0 & 9 & 7,8 & 12 & 17,0 & 11 & 17,0 \\
Especialistas & 3 & 8,6 & 3 & 2,6 & 1 & 1,0 & 4 & 6,0 \\
Pesquisadores & - & - & - & - & - & - & - & - \\
Outros & 1 & 2,9 & 1 & 0,9 & - & - & - & - \\
Não sei & 5 & 14,2 & 2 & 1,8 & - & - & - & - \\
Sem respostas & 4 & 11,4 & 9 & 7,8 & - & - & 4 & 6,0 \\
\hline TOTAL & 35 & 100,0 & 115 & 100,0 & 72 & 100,0 & 66 & 100,0 \\
\hline
\end{tabular}


Os dados acima referidos confirmam uma antiga aspiração no ambiente da Faculdade de Medicina expressa, quer por docentes como por alunos e residentes, no sentido de se dar prioridade à formação do médico geral. Essa mesma tendência foi manifestada no levantamento de opiniões realizado na Faculdade de Medicina da U.F.M.G. ${ }^{13}$.

Quando inadagado se "ao receber o diploma de médico você teve ou terá condições de exercer com segurança as funções de médico geral", o conjunto de residentes e internos respondeu "não", inexistindo diferença entre "sim" e "não" no caso dos residentes, embora a resposta "não" fosse a mais freqüente. Assim, a proporção de respostas "não" dadas pelos internos foi maior que a dos residentes. Essas opiniões referendam aquelas obtidas dos docentes para a questão 2 , ratificando a falta de preparo do aluno de graduação para atuar como médico geral. A opinião dos residentes neste sentido, provavelmente foi atenuada pela experiência e aprendizado auferidos durante a residência ou pelas melhores condições de aferir o seu real aprendizado.

\subsection{Características dos Cursos e Currículos atuais}

Em relação à "posição de sua disciplina no atual currículo", os docentes do básico e do aplicado opinaram de forma similar no sentido de mantê-la ( $74 \%$ e $70 \%$, respectivamente). Quanto às "disciplinas que poderiam ser suprimidas do atual currículo", ambos os grupos não souberam em sua maioria se definir ( $86 \%$ e $50,4 \%$, respectivamente). Houve $23 \%$ de respostas afirmativas a essa questão para os docentes do curso aplicado, entre as quais foram citadas as seguintes disciplinas: radioterapia, radiodiagnóstico, medicina nuclear e física radiobiomédica. Alguns docentes fizeram considerações interessantes sobre a atual pulverização do currícu- lo e necessidade em reorganizá-lo com disciplinas mais abrangentes. Entre os docentes do curso básico, apenas $2(6 \%)$ responderam afirmativamente, porém sem especificá-las.

A análise dos procedimentos didáticos, de acordo com sua freqüência de utilização no curso básico mostrou que houve adoção predominante de exposição oral e aula prática.

As características dos cursos e currículos foram avaliadas também por internos e residentes, verificando-se:

a) a "enfermaria" foi o local em que se deu maior ênfase ao ensino de aplicação;

b) o "tempo disponível para estudo" no curso de aplicação foi considerado insuficiente;

c) as "preocupações prioritárias dos departamentos" relacionaram-se à pesquisa e outras, diversas das demais alternativas formuladas (ensino de graduação, residência, assistência médica, etc.);

d) os docentes das áreas básica e aplicada, no que diz respeito a "quantos estão adequadamente preparados para ensinar" foram considerados da seguinte maneira: para intemos e residentes a proporção de "poucos" foi maior no que diz respeito aos docentes da área básica, não havendo diferença entre a proporção de "número regular" e "poucos" para os docentes da área aplicada; para ambos os grupos a proporção de "poucos" foi maior para os docentes do básico do que para os do aplicado; saliente-se a pior cotação para os docentes do básico quanto a esta característica;

e) as modalidades didáticas de maior rendimento foram: "contato direto com o docente", "demoristração prática" e "discussão em grupo";

f) o estudo foi "prioritariamente motivado pelo curso";

g) o curso médico desenvolveu-se, de um modo geral, de "forma passiva";

h) consideraram-se "a par dos problemas de 
saúde no Brasil e na região";

i) durante o curso "não adquiriram noção da realidade profissional, fora da faculdade de medicina";

j) "ao final do curso estavam aptos a manter bom relacionamento médico-paciente".

Em relação à linha de formação médica pretendida, na avaliação anteriormente referida, são aspectos inadequados: a predominante utilização da enfermaria, o insuficiente tempo para estudo, a forma passiva que prevaleceu no aprendizado $\mathrm{e} o$ desconhecimento da realidade profissional fora da Faculdade. Quando se elege como objetivo a formação do médico geral, as apreciações sobre as preocupações prioritárias dos docentes não incluindo aquelas com o curso de graduação $e$ o número pequeno de docentes preparados para o ensino são aspectos igualmente desfavoráveis e que implicam em reformulações.

\subsection{Rendimento dos Cursos atuais}

As respostas às questões sobre o rendimento obtido nos cursos ministrados pelo Departamento e pela Disciplina, para os docentes do ciclo básico e do aplicado mostraram que houve distribuição semelhantes para "satisfatório" e "insatisfatório". Embora não havendo diferença, sempre foram maiores as proporç̃̃es de "satisfatório" para os docentes do aplicado, o contrário ocorrendo para os docentes do básico. A comparação entre os dois grupos não revelou diferença entre as proporções de respostas.

Entre os docentes do aplicado as proporções das respostas classificadas segundo todos os critérios estabelecidos não diferiram. Já para os do curso básico, observou-se maior proporção de respostas dos docentes de Patologia.

Entre os três fatores que prevaleceram como explicação para o baixo rendimento didático, "insuficiência numérica de docentes" e "condições inadequadas para ensino prático" foram comuns aos dois grupos. Além destes, para os do básico foi apontado "turmas de alunos muito numerosas" e para os do aplicado "carga horária inadequada".

Tanto os docentes do básico quanto do aplicado dividiram-se uniformemente quando responderam "se o aluno tem base ou não para aprender o conteúdo das disciplinas que ministram"; por outro lado, ao explicarem as razões da "falta de base" responderam com alternativas, em geral, não constantes do questionário tornando assim impossível extrair conclusões.

Dos docentes do básico, 77\% respondeu que a "estruturação atual do curso de sua disciplina dá condições para que $o$ aluno aplique os conhecimentos no curso clínico".

Os residentes e internos indagados sobre o "rendimento dos cursos atuais" consideraram significantemente "pouco úteis" as informações recebidas no ciclo básico. Em relação à "contribuição dos cursos do ciclo básico para a formação médica global", internos e residentes consideraram-na "pequena" sendo a proporção de respostas dos internos maior do que a dos residentes.

A necessidade de modificar o curso básico e o de aplicação com intenção de melhorar o aprendizado profissional foi considerada pela quase totalidade dos internos e residentes.

As principais causas de falha no curso básico especificadas pelo conjunto de internos e residentes foram:

1) "falta de integração com o curso de aplicação" (predominante nos dois grupos);

2) "docentes mal preparados";

3) "desinteresse dos docentes";

4) "turmas muito numerosas";

5) "conteúdo programático inadequado ao ciclo clínico"e

6) "posição inadequada das disciplinas no currículo".

No curso de aplicação, as dificuldades do ensino foram consideradas de maneira se- 
melhante por internos e residentes. "Cursos mal organizados" foi a resposta prevalente para ambos, sendo que entre os internos obteve proporção semelhante àquelas dadas para "docentes mal preparados" e "cursos distanciados da realidade de saúde".

Para a análise das respostas de internos e residentes à questão: "ao concluir o curso de graduação você se considera (ou considerava) capacitado a", os 40 ítens foram reunidos em 3 grupos:

1) relacionado com diagnóstico e terapêutica (20 ítens);

2) relacionado com interpretação de exames subsidiários (7 ítens);

3) relacionado com habilidades técnicas (13 ítens).
A cada ítem corresponderam as alternativas "sim" e "não".

Dentro de cada um dos grupos as proporções de respostas "sim" aos diversos ítens diferiram para internos e residentes. As proporções de respostas "sim" pelos entrevistados variaram de 0 a $100 \%$.

A tabela 4 mostra que, de um modo geral, os residentes tiveram percentuais médios de "sim" um pouco mais elevados do que os dos internos, salientando-se que os maiores percentuais médios se observaram para os ítens envolvidos com capacitação em diagnóstico e terapêutica, enquanto os percentuais mais baixos foram registrados para habilidades técnicas.

\section{TABELA 4 - DISTRIBUIÇÃo DAS PERCENTAGENS MÉDIAS DE RESPOSTAS "SIM" DE ACORDO COM GRUPOS DE ITENS (CAPACITAÇÃO) PARA INTERNOS E RESIDENTES (Botucatu, 1978).}

\begin{tabular}{|l|c|c|c|}
\hline \multicolumn{1}{|c|}{ Respostas } & $\begin{array}{c}\text { Interno } \\
(\%)\end{array}$ & $\begin{array}{c}\text { Residente } \\
(\%)\end{array}$ & $\begin{array}{c}\text { Total } \\
(\%)\end{array}$ \\
\hline Itens
\end{tabular}

Analisando as capacitações explicitadas no grupo referente a diagnóstico e terapêutica verificou-se que:

a) foram de maior freqüência para os internos e residentes "diagnosticar e tratar desidratação", "diagnosticar e tratar infecções urinárias", "diagnosticar e tratar diarréia"; para os internos ainda - "orientar a alimentação e imunização no primeiro ano de vida" e "diagnosticar e tratar desnutrição infantil"; para os residentes acrescente-se - "diagnosticar e tratar parasitoses intestinais" e "diagnosticar e tratar úlcera péptica". b) foram de menor freqüência para ambos, "diagnosticar e tratar choque", "diagnosticar e tratar transtôrnos funcionais de origem psíquica" e "tratar as principais alterações do ciclo menstrual".

Para as capacitações em interpretação de exames subsidiários:

a) foram mais freqüentes "interpretar exames bacteriológicos"; "interpretar exame de urina de rotina" e "interpretar o henłograma", para internos e residentes;

b) foram de menor freqüência - para os internos e residentes a "interpretação do E.C.G."; apenas para os internos, "inter- 
pretar radiografias simples" e para os residentes, "interpretar exames sorológicos";

Os ítens relacionados a habilidades técnicas que apresentaram:

a) as maiores frequêencias para internos e residentes foram - "colocar sonda uretral"; "colocar sonda retal e/ou gástrica" e "realizar partos normais"; ainda para os internos, "realizar punção liquórica lombar" e para os residentes; "realizar e interpretar o toque retal";

b) as menores frequências para os internos e residentes foram - "imobilizar corretamente membros fraturados" e "realizar pequenas cirurgias"; ainda para os internos "realizar punção de tórax" e, para residentes "passar sonda endotraqueal".

\subsection{Integração Curricular}

Tanto docentes do básico como do aplicado responderam prevalentemente que há disciplinas de seus cursos que poderiam ser ministradas de modo integrado. No caso de respostas afirmativas foram citadas numerosas sugestões de integração em cada ciclo e mesmo entre os dois ciclos. Assim, houve por parte dos docentes do básico sugestões para integrações internas e para $42 \%$ deles propostas para integração entre disciplinas básicas e aplicadas, envolvendo quase sempre anatomia com disciplinas cirúrgicas; microbiologia, imunologia e parasitologia com epidemiologia e/ou anatomia patológica. Apenas $32 \%$ dos docentes do aplicado propôs integração entre disciplinas dos dois ciclos, enquanto a maioria deles sugeriu integração de suas próprias disciplinas, clínicas e cirúrgicas com, principalmente, anatomia patológica. Outras freqüentes sugestões referiram-se a medicina preventiva com disciplinas clínicas; gastro-clínica com gastro-cirúrgica; nefrologia com urologia e cardiologia com cirurgia toráxica. Docentes do departamento de pediatria quase sempre sugeriram integra- ção com moléstias infecciosas, neuropediatria, psicologia infantil, dermatologia, otorrinolaringologia e obstetrícia.

Docentes do básico e do aplicado, residentes e internos responderam, em geral, afirmativamente sobre o conhecimento de "assuntos repetidos em diferentes disciplinas". Apenas, para os docentes do básico não houve diferença quanto à proporção de resposta "não sei". Interessante registrar que, no levantamento de opiniões efetuado na Faculdade de Medicina da UFMG, $85 \%$ das respostas a essa questão foram afirmativas, principalmente por parte dos residentes e alunos ${ }^{13}$.

Reiterando que, praticamente, inexiste integração entre cursos básico e aplicado, $83 \%$ dos docentes do básico, além de declararem não haver integração entre suas disciplinas e as do ciclo aplicado, consideraram-se "pouco informados" ou "sem nenhuma informação" quanto ao conteúdo dos programas do curso de aplicação. Tal situação parece ser constante na maioria dos cursos de Medicina do país, tendo sido ratificada no estudo da FMUFMG, em que $85 \%$ de docentes e alunos reconheceu que não há integração dos dois ciclos ${ }^{13}$.

As razões da "não integração" mais apontadas pelos professores do básico foram duas: "ausência de um colegiado que centralize todos os cursos das duas áreas" (34\%) e "falta de entrosamento de docentes das áreas básica e profissional” (34\%).

\subsection{Alternativas de modificações de currí- culo e curso}

Grande parte das respostas às questões agrupadas neste tópico constitue alternativas ou mesmo propostas de reformulação ou de fundamentação para eventuais modificações.

Assim, o "conhecimento das doenças de maior ocorrência em nossa região" foi considerado condição de relativa utilidade 
(49\%) ou desnecessária ( $29 \%$ ) para o planejamento dos cursos do ciclo básico, enquanto para os docentes do aplicado foi considerada condição indispensável ( $46 \%$ ) ou de relativa utilidade (45\%).

Foi quase unânime a opinião de todos os grupos de que o corpo docente deve se preocupar também com a formação humanística do estudante.

Quanto à questão "desde o primeiro ano do curso de Medicina os alunos devem ter contato com serviços de saúde da comunidade", observou-se prevalência de respostas afirmativas em todos os grupos. A menor proporção de respostas "sim" foi a dos professores do curso básico (34\%), menor que as proporções dos demais 3 grupos, que não diferiram entre si. A proporção de "sim" dos docentes do aplicado foi de $63 \%$, com proporção maior de respostas dos docentes da anatomia patológica, em relação aos demais grupos. As proporções de respostas afirmativas dos internos e residentes, respectivamente, $81 \%$ e $65 \%$ não diferiram, mas a maior percentagem relacionada aos internos pode significar experiência mais próxima com os serviços da comunidade que tiveram em 1978, ao contrário da menor taxa dos docentes do aplicado e dos residentes face à centralização de suas atividades no Hospital das Clínicas. Tendência semelhante verificou-se no inquérito realizado na FMUFMG, para os três grupos de respondentes ${ }^{13}$.

Em termos de opinião sobre "comó considera a participação sistemática de sua disciplina na fase de aplicação do curso de Medicina", os professores do básico, em $75 \%$ das vezes julgaram-na vantajosa, mostrando-se $29 \%$ cépticos quanto à viabilidade $\mathrm{e}$ $46 \%$ crédulos quanto à mesma. Nenhum docente se pronunciou a favor da alternativa "desvantajosa para o rendimento didático".

Quando indagados sobre a integração de disciplinas básicas e aplicadas do 10 ao 60 ano, $80 \%$ dos docentes do básico consi- derou-a vantajosa, sendo que $43 \%$ julgou-a viável e $37 \%$ inviável. Os docentes do departamento de morfologia, de modo geral, acharam vantagem nas duas últimas propostas, mas foram os que menos as consideraram viáveis.

"Desde o primeiro ano do curso médico os alunos devem ter contato com doentes" e "aprender técnicas simples e cuidados à saúde" na opinião respectivamente de $48 \%$ e $68 \%$ dos docentes do aplicado, não se registrando diferença nas proporções de "sim" $(48 \%)$ e "não" (38\%) para a primeira questão. Houve para a segunda maior proporção de respostas dos docentes de anatomia patológica.

"A formação clínica do 30 ao 6 ? ano deve partir do ensino da clínica geral", segundo a maioria $(81 \%)$ dos docentes do aplicado e "deve partir do ensino de especialidades" segundo a minoria (10\%) deles. A proporção de respostas para a primeira alternativa anterior emitida pelos docentes do grupo "clínico" foi menor que a dos demais grupos; o inverso ocorreu entre os "especialistas" com relação aos docentes das áreas "gerais". Estas opiniões contrariam a prática atual de formação clínica, uma vez que em vários departamentos o ensino atual não está partindo dos "aspectos gerais".

Quando se perguntou sobre a preferência quanto ao sistema $2 \times 2 \times 2$, notou-se dificuldade de definição por parte dos docentes do curso aplicado, a julgar pelas proporções de respostas "sim" e "não sei", respectivamente, de $49 \%$ e $32 \%$.

Por outro lado, quando indagados sobre o tempo de duração do internato, os docentes deram preferência para 2 anos (75\%).

Em relação às áreas em que o aluno deve ser treinado no internato de 2 anos, $50 \%$ dos docentes optou "pelas áreas gerais, incluídas as especialidades", enquanto $39 \%$ optou exclusivamente pelas 5 áreas gerais (clínica médica, clínica cirúrgica, pediatria, 
ginecologia, obstetrícia e saúde pública). Curso integrado no 4 ? e 50 anos, em caso do internato ser realizado apenas durante o 6 ? ano, foi a opção de $60 \%$ dos docentes.

Quanto aos locais preferenciais de aprendizado durante o curso médico, foram apontados o "hospital-escola" (97\%) e "centros de saúde" (75\%). Na FMUFMG, cêrca de $80 \%$ das respostas obtidas neste sentido propôs que o curso de Medicina deveria incluir atendimento médico em bairros, favelas, centros de saúde, etc., com a orientação de professores ${ }^{13}$.

Não houve diferenças nas proporções de respostas indicativas do local preferencial para ensino dentro do hospital-escola observando-se $48 \%$ de respostas para "ambulatório + enfermaria" e $37 \%$ de respostas para "ambulatório". Apenas $9 \%$ dos docentes optou pelo uso preferencial de enfermaria.

Ao final do questionário distribuído aos docentes do curso de aplicação foi colocado um "anexo fundamental" no qual solicitou-se a especificação de "cinco ítens relacionados ao programa de sua disciplina correspondentes às habilidades indispensáveis que $o$ aluno deve adquirir para, ao final do 60 ano, exercer as atividades de médico geral".

Dos 115 docentes que responderam ao questionário, $105(91 \%)$ atenderam a esta solicitação. Setenta e quatro (70\%) deles explicitaram os ítens de forma precisa e objetiva, sobretudo dirigidos para habilidades relacionadas à esfera cognitiva.

O amplo e variado conteúdo assim obtido constituir-se-á em subsídio fundamental para os estudos de reformulação em andamento na Faculdade de Medicina de Botucatu.

\section{Comentários Finais}

O Curso de aplicação na Faculdade de Medicina teve início em setembro de 1965, obedecendo a planejamento e estruturação fundamentados nos seguintes princípios:

1. O ensino integrado no curso de aplicação;

2. O funcionamento do hospital universitário basicamente como um centro de ensino e não de assistência médica;

3. O treinamento do estudante dentro e fora do hospital, dando ênfase à medicina social e comunitária;

4. A introdução do ensino formativo no curso de medicina.

Desta forma esperava-se conseguir a formação do médico geral, apto a exercer suas atividades dentro dos recursos disponíveis em nossas comunidades ${ }^{6}$.

Em 1968, vários destes princípios foram reafirmados, sobretudo o da "formação do médico geral apto a satisfazer as demandas crescentes do interior de nosso país", em documento elaborado pelo então Setor de Ciências Médicas da FCMBB ${ }^{7}$.

$O$ levantamento de opiniōes, objeto do presente trabalho mostrou que, decorridos 14 anos do primeiro marco referencial, vários dos postulados básicos não foram cumpridos, a começar pela caracterização do médico que a Faculdade vem formando. A integração não tem presidido os cursos ministrados; o currículo pulverizou-se pelo grande elenco de disciplinas: o aprendizado é passivo e distanciado da realidade profissional e de saúde. $O$ ensino de graduação não parece ser a primeira prioridade dos departamentos e, por fim, faltam ainda condições e recursos humanos qualificados para melhorar o seu rendimento.

Tendo em vista a realidade atual da assistência à saúde e frente à situação do "aparelho formador" - no caso da Escola Médica - haveria duas principais opções quando se pretende estabelecer o seu rumo:

a) formar profissionais passiveis de fácil absorção pelo mercado de trabalho, cada vez mais assalariado, na emprêsa médica ou na instituição pública; ou 
b) a partir da aceitação da irreversibilidade da prática institucional da medicina, formar médicos tecnicamente mais adequados às necessidades de saúde da população, ao mesmo tempo que exercitados quanto ao pensamento crítico ${ }^{4}$.

Neste sentido, as sugestões oferecidas pelos docentes, alunos e residentes, assim como as definições de habilidades não incluídas no presente estudo, serão de valia não apenas para a op̧̧ão do caminho a seguir, como também para a concretização de coerentes reformulações de currículo e curso.

\section{Referências Bibliográficas}

1 ALMEIDA, D.B.; et alii - Análise da evolução do curso de aplicação em Medicina da Faculdade de Ciências Médicas e Biológicas de Botucatu a partir de 1966. In: Reunião da Associação Brasileira de Escolas Médicas, Brasília, 1970. Anais, Rio de Janeiro, ABEM, 1971. p.121-40.

2 ALMEIDA, D.B.; et alii - Projeto de reestruturação do curso de aplicação em Medicina na Faculdade de Ciências Médicas e Biológicas de Botucatu. In: Reunião da Associação Brasileira de Escolas Médicas, Brasilia, 1970. Anais, Rio de Janeiro, ABEM, 1971. p.141-62.

3 ALMEIDA, D.B. \& MAGALDI, C. - Medicina Humana na FCMBB - Revista da Associação de Docentes da FCMBB, Botucatu, 1:49-55, 1974.

4 CORDEIRO, H.A. \& QUADRA, A.A.F. - 0 feitiço das reformas curriculares no Ensino Médico - Revista Brasileira de Educação Médica 2:15-21, 1978.
5 DUTRA DE OLIVEIRA, J.E.; et alii - Uma experiência de ensino formativo na Faculdade de Medicina de Botucatu. Revista da Associação Médica Brasileira. 13:406-408, 1967.

6 DUTRA DE OLIVEIRA, J.E. - Plano de Ensino Médico na Faculdade de Botucatu em São Paulo. Revista da Associação Médica Brasileira. 12:323-330, 1966.

7 FACULDADE DE CIÊNCIAS MÉDICAS E BIOLÓGICAS DE BOTUCATU - Resultado do Estado conjunto sobre "Filosofia de Ensino na FCMBB. Setor de Ciências Médicas, 1968. Mimeografado.

8 FLEISS, J.L. - Statistical methods for rats nad proportions - New York, John Wiley \& Sons, 1973, 223p.

9 GOODMAN, L.A. - Confidence Intervals for contrasts among multinomial populations. Annals of Mathematical Statistics 35(2):716-725, 1964.

10

- On Simultaneous confidence intervals for multinomial proportions Technometrics 7(2):247-254, 1965.

${ }^{11}$ MAGALDI, C.; et alii - Internato de doenças tropicais e Infecciosas e Medicina Preventiva. In: Reunião da Associação Brasileira de Escolas Médicas, 9., Curitiba, 1971. Anais. Rio de Janeiro, ABEM, 1972. p.179-87:

12 O MÉDICO de família. In: Congresso Brasileiro de Educação, Londrina 22 a 24 de novembro de 1978, Anais. Rio de Janeiro, ABEM, 1979. p.23-138. Tema I.

${ }^{13}$ O PROCESSO do desenvolvimento curricular em Educação Médica na Universidade Federal de Minas Gerais, Belo Horizonte, UFMG. Imprensa Universitária. Publicação n.? $643,1976$.

14 SEMINÁRIO SOBRE A FORMAÇÃO DO MÉDICO GENERALISTA, Campinas, 24 a 27 de maio de 1978. In: Revista Brasileira de Educaf̧āo Médica, Rio de Janeiro, Suplemento, 1. 1978. 